\title{
Research on the establishment and operation management of flexible organization
}

\author{
Weidong $\mathrm{Qu}^{* 1, \mathrm{a}}$, Hongyan $\mathrm{Niu}^{1, \mathrm{~b}}$ \\ ${ }^{1}$ Baoding Electric Power Vocational and Technical College Baoding, Hebei, China
}

\begin{abstract}
This paper puts forward the necessity of establishing flexible organization for enterprises to cope with external challenges, analyzes the characteristics and main problems of flexible organization, and probes into some suggestions on the establishment and operation management of flexible organization. In order to realize the flexible management of the project organization, it is necessary to explore the continuous improvement in practice, so as to achieve its role in effectively invigorating the stock and efficiently integrating resources.
\end{abstract}

\section{Introduction}

In recent years, with the increasing pressure of scientific and technological progress, system reform and economic transformation, the complex and changeable and uncertain business environment of enterprises has been greatly enhanced, posing new challenges to Chinese enterprises in the forefront of the era of change. How to deal with these challenges has become an important management issue.

As an important way of labor organization, flexible team is an innovative measure for human resource management mechanism to adapt to change. The creation and implementation of various forms of flexible organizations to further optimize the allocation of human resources is regarded as a strategic tool for today's enterprises to cope with external challenges. This paper discusses some key issues in the establishment and operation of flexible organizations in enterprises, so as to quickly respond to new market demands and adapt to the needs of new business and new model development.

\section{The characteristics and research significance of flexible organization}

The so-called flexible organization refers to the organization that has the ability to continuously learn, develop and innovate, systematically and continuously integrate internal and external resources to deal with the challenges of environmental change and causal ambiguity.

Flexible organization has greater flexibility both in the management system and in the establishment of the organization. It has a strong adaptability to the business environment of the enterprise and shows a strong adaptability, flexibility, innovation and learning ability. Flexible organization has become a new organizational form pursued by enterprises all over the world [1].

Flexible organizations usually have the characteristics

\footnotetext{
a* Corresponding author: 39400920@qq.com

bniuhongyan2005@163.com
}

of strong professionalism, loose organization, extensive personnel composition, false responsibilities or difficult to implement. However, they are indispensable in responding to external challenges, adapting to new business needs, carrying out engineering projects and other specific tasks.

Therefore, it is necessary to study the construction of these flexible organizations, and investigate the key factors and relationships among them, so that they can play a greater role.

Past the flexible organization of related studies mostly based on western enterprise situation, the dispersion in the strategic management, organizational change, operation management and human resources management, and many other research areas, to explore how the organization from manufacturing, organizational structure, operational processes, human resources, financial self adjustment and dynamic adaptation, has a vague concept, disperse system and inspection defects such as the lack of Chinese enterprise practice.

In view of the existing research gaps, this paper discusses how Chinese enterprises create and operate flexible organizations in the ups and downs of the external competitive environment, so as to adapt to the requirements of new production, programs, engineering projects and other specific affairs, and respond to the challenges through innovation.

\section{Flexible Organizations In The Actual Operation Of The Easy To Appear Problems}

\subsection{Job Responsibilities}

Because the job responsibilities of flexible organizations can have greater flexibility, they can form a combination of reality and reality according to the actual work needs, 
which can be applied to the responsibility requirements of project work as much as possible. However, in the actual work, the actual capacity of such organizations is often not fully considered, and there is a general but empty situation in the responsibility setting that is separated from the reality.

Goals are too high to be achieved, the scope is too large to be taken into account, the program is too general and often poorly operated.

\subsection{Personnel composition}

The establishment of flexible organization is mainly to complete a new business and form a project team with corresponding personnel as members. According to the business needs, coordinate the use of internal and external resources, break the boundaries between departments, break the staffing limit. In this way, the personnel composition is relatively wide, the horizontal span is large, the relationship between superiors and subordinates is relatively loose, which is conducive to the formation of a democratic atmosphere, the absorption of talents from different professions, and easy to give full play to personal initiative and enthusiasm for work.

The selection and appointment of personnel with high leadership and academic positions can help to win resources and expand their influence by virtue of their influence. However, if more of these "double high" personnel are selected, and fewer professionals are engaged in practical work, thus being top-heavy, the work is not easy to carry out.

\subsection{Operation}

The flexible organization is more flexible in operation, which is conducive to forming a reasonable and efficient operation mechanism, giving full play to the role of organizations at all levels, and forming working force. However, in actual work, because the organization is relatively loose, the resultant force is not easy to form. Because the program is too extensive, the coordination workload is large. Because the job responsibilities are empty, it is often difficult to carry out [2].

\subsection{Performance appraisal}

In the assessment and evaluation, flexible organizations are often different from rigid organizations with fixed organizations, fixed procedures, fixed time, and relatively systematic assessment and evaluation according to job responsibilities. There is often a lack of assessment of flexible organizations, not to mention work improvement requirements or corresponding rewards and punishments.

\section{Research on the organizational structure of flexible organization}

\subsection{Types and advantages and disadvantages of business organization}

Organizations achieve common goals through management actions. There are several common types of organizations.

\subsubsection{Linear functional system}

At present, the vast majority of our single strategy SMEs uses this form of organizational structure. In this form of organizational structure, the enterprise management organization and personnel are divided into two categories. One is the straight-line leading organization and personnel, who exercise command over the organization at all levels according to the principle of unified command. The other is the functional organization and personnel, who are engaged in the management of various functions of the organization according to the principle of specialization.

The direct leading organization and personnel shall have certain right of decision and command over the direct subordinate organization and personnel within the scope of their duties and assume full responsibility for the work of their own department. The functional organizations and personnel have the functions of the leading organization's functional staff and functional supervision, and cannot give orders to the direct departments, but can only provide business guidance and relevant business supervision.

\subsubsection{Divisional System}

Due to the development of enterprises, an enterprise strategy cannot solve all the problems. According to the different mission of enterprises, they are divided into different independent accounting departments, which is the result of the development of linear functional system. It is applicable to enterprises with multiple sub-strategies.

Divisional system is a hierarchical management, classification of accounting, a form self-sustaining, that is, a company according to region or according to the enterprise mission is divided into a number of different business units, from product design, raw material procurement, cost accounting, product manufacturing, to product sales enterprise mode of operation, all shall be the responsibility of the department and its subordinate factory, implements the independent accounting, independent operation, the company headquarters to keep only the personnel decisions, budget control and supervision of power, and through the profit and other indicators to control group.

\subsection{3 matrix organization}

A form of organization formed in order to improve the shortcomings of the linear function system, such as poor horizontal connection and lack of flexibility.

Its characteristic in around a specialized task to set up cross-functional departments specialized agencies, such as to form a special product (project) team to work in the new product development, in the research, design, test, manufacture different stages, sent by the related departments to participate in, trying to do how to coordinate the activities of the relevant departments to ensure the completion of the task. 
The organizational structure is fixed, but the personnel are fluid. Whoever is needed can come and leave when the task is done. Project teams and leaders are also organized and appointed on an AD hoc basis. Upon completion of the task, the staff shall be disbanded and returned to their original units.

The advantages and disadvantages of the above organizational structure are shown in Table 1.

Table1. Types and strengths and weaknesses of organizations

\begin{tabular}{|l|l|c|c|}
\hline $\begin{array}{c}\text { Type of } \\
\text { organizatio } \\
\text { nal } \\
\text { structure }\end{array}$ & \multicolumn{1}{|c|}{ advantages } & disadvantages & $\begin{array}{c}\text { Applicable } \\
\text { situations }\end{array}$ \\
\hline $\begin{array}{l}\text { Linear } \\
\text { functional } \\
\text { system }\end{array}$ & $\begin{array}{l}\text { Centralization and } \\
\text { unification } \\
\text { enterprise } \\
\text { management system }\end{array}$ & $\begin{array}{c}\text { The coordination and } \\
\text { coordination between } \\
\text { functional departments } \\
\text { is poor, and the work } \\
\text { efficiency is low }\end{array}$ & $\begin{array}{c}\text { Single } \\
\text { strategy } \\
\text { SMEs }\end{array}$ \\
\hline $\begin{array}{l}\text { Divisional } \\
\text { System }\end{array}$ & $\begin{array}{l}\text { It has high stability and } \\
\text { good adaptability }\end{array}$ & $\begin{array}{l}\text { There are more people, } \\
\text { higher costs and poor } \\
\text { coordination among } \\
\text { business divisions }\end{array}$ & $\begin{array}{c}\text { Multiple sub- } \\
\text { strategic } \\
\text { enterprises }\end{array}$ \\
\hline $\begin{array}{l}\text { matrix } \\
\text { organization }\end{array}$ & $\begin{array}{l}\text { Lateral mobility and } \\
\text { flexibility }\end{array}$ & $\begin{array}{c}\text { Not enough incentive } \\
\text { and punishment means }\end{array}$ & $\begin{array}{c}\text { It is suitable } \\
\text { for horizontal } \\
\text { collaboration } \\
\text { and problem- } \\
\text { solving } \\
\text { projects }\end{array}$ \\
\hline
\end{tabular}

\subsection{Organizational architecture design for flexible organizations}

Generally speaking, there is no fixed mode for organizational structure design, which varies according to the production technology characteristics and internal and external conditions of enterprises. However, the ideas and rules of organizational structure reform can be used for reference.

Organizational structure change should address the following four structures:

- Functional structure. The successful operation of a business requires multiple functions to play a role together. Therefore, in the design of organizational structure, we should first determine which functions are required by the business operation, and then determine the proportion and relationship between each function.

- Hierarchy structure, namely the composition of each management level, that is, the organization needs to set up several management levels vertically.

- Department structure, namely the composition of each management department, that is, how many departments need to be set up horizontally in the organization.

- $\quad$ Structure of authority, that is, the division of labor and mutual relations among different levels and departments in terms of authority and responsibility.

In order to avoid the shortcomings of poor horizontal connection and lack of elasticity of linear function system, flexible organization should adopt "matrix" organization platform to carry out flat management [3].

The "matrix" organization platform is built with the entity organization as the horizontal organization and the flexible organization as the vertical organization. Each position on the platform not only accepts the leadership of the horizontal organization, but also performs the tasks of the vertical organization.

\section{Several Key Issues In The Operation And Management Of Flexible Organizations}

\subsection{The concept of flexible organization}

More attention should be paid to the role of consciousness in loosely organized groups.

- $\quad$ One is to have the ability to put forward a good working concept and enough to influence the core.

- $\quad$ Second, if the concept is suitable for this work, so that the work does not lose the right direction.

- Third, the concept can be accepted by everyone, forming the conscious awareness of each member of the collective, and can be consistently implemented in the work.

The human factor in a flexible organization is more complex, more prominent, and more difficult to control in real time. A unified, suitable for work, accepted and implemented by everyone is the soul of guiding work and guiding the direction.

\subsection{Exploring post setting and personnel allocation of flexible organizations according to business realities}

According to the period of the target task, the size and complexity of the follow-up business volume, and taking into account the existing human resources, the personnel allocation mode combining specialized and concurrent work is adopted. Full-time staff temporarily leaves the original post and return to the original post after the end of the task. Part-time employees do not change their original posts and can be members of think tanks.

After full-time and part-time staff join the flexible team, the team leader shall divide the tasks, each performing his or her own duties and responsibilities. Broaden the horizontal span of personnel composition, so that the leadership relationship is loose. Break through the boundaries between departments, break through the staffing restrictions, and absorb talents of different specialties.

The team leader is responsible for the management and promotion of the whole project and is directly responsible for the special work tasks. Part-timers can be fluid at various stages of research, design, and experimentation, coming in as needed and leaving when the task is done. According to the work nature and content of the flexible team, the flexible team studio is set up to solidify the office space for full-time staff and provide convenience for their work 


\section{3 the relationship between flexibility and rigidity}

In the setting of job responsibilities, we should achieve the reality in the virtual, the virtual and the real is appropriate. In particular, we must do a good job of key responsibilities and core tasks, so that responsibilities have a focus and tasks can be implemented [4].

In terms of personnel composition, there are part-time think tank personnel and full-time staff, and the focus should be placed on "leaders" who can put forward work ideas and "capable of working" staff. In terms of operation mechanism, attention should be paid to the combination of rigidity in operation procedure and flexibility in organization idea, and the procedure should be wide in general work and strict in core task.

\subsection{Establish a reasonable assessment and salary incentive system}

Establish a reasonable assessment system, the assessment should not be too detailed and too strict, but highlight the key points, the key responsibilities, core tasks.

After the establishment of the flexible team, the work objectives are defined and the assessment indicators are set. Set up the internal flexible team and bring the completion of the project team into the operation monitoring, make special reports in the quarterly work meeting, strengthen the process control and ensure timely error correction.

For the flexible team, KPI performance assessment tool was adopted to conduct key performance assessment for the project team, which was decomposed to each quarter. OKR performance assessment tool is adopted for team members. According to the key goals of the team, team members independently set personal work goals and key achievements, and track, supervise and assess them quarterly[5].

In terms of compensation management, we should establish a distribution mechanism of self-responsibility for profits and losses and profit sharing.

According to the annual assessment results, the team will be given a one-time performance reward. The project leader shall make annual evaluation based on the performance assessment results of the members, and distribute the rewards twice. At the same time, nonmaterial incentives, such as boss experience and sense of achievement, are injected to enable employees to obtain all-round incentive drive, so that flexible organizations can operate smoothly with a small number of employees.

\section{Conclusion}

Based on the research of flexible organization in enterprises, this paper analyzes the problems that flexible organization is prone to in the actual operation, and discusses several key problems in the operation and management of flexible organization, so as to provide certain reference for enterprises to make more scientific and reasonable decisions. Of course, this study also has some shortcomings, which need to be empirically tested in subsequent studies.

\section{References}

1. Wang Fengxia, The main mode of enterprise organization in the 21st century, Business Research.Heilongjiang ,vol.11, pp. 24, October 2002.

2. Huang Jinhong, Analysis of flexible structure, Economic theory research. Wuhan,vol. 3, pp. 28-29, February,2006.

3. Li Hongde, Construction of flexible organization in university teaching. Journal of henan mechanical and electrical college. Zhengzhou,vol.7, pp. 87-88, April ,2012.

4. Liu Zhengying, Exploration on the Scheme of Constructing the Think Tank of Electric Power Enterprises by the Flexible Organization Mode. Gansu science and technology. Lanzhou,vol.1, pp. 110-111, January ,2019.

5. Chen Yali Research on Performance Appraisal of Construction Enterprises under Flexible Organization.China's collective economy. Beijing,vol.4, pp. 87-88, April,2017. 